\title{
Dynamic Stress-Strain Behaviour of Steel Fiber Reinforced High-Performance Concrete with Fly Ash
}

\author{
Tan Chien Yet, R. Hamid, and Mudiono Kasmuri \\ Department of Civil and Structural Engineering, Faculty of Engineering and Built Environment, \\ Universiti Kebangsaan Malaysia, Selangor, 43600 Bangi, Malaysia \\ Correspondence should be addressed to R. Hamid, roszilah@eng.ukm.my
}

Received 2 August 2012; Accepted 18 October 2012

Academic Editor: Paola Bandini

Copyright ( 92012 Tan Chien Yet et al. This is an open access article distributed under the Creative Commons Attribution License, which permits unrestricted use, distribution, and reproduction in any medium, provided the original work is properly cited.

The addition of steel fibers into concrete mix can significantly improve the engineering properties of concrete. The mechanical behaviors of steel fiber reinforced high-performance concrete with fly ash (SFRHPFAC) are studied in this paper through both static compression test and dynamic impact test. Cylindrical and cube specimens with three volume fractions of end-hooked steel fibers with volume fraction of $0.5 \%, 1.0 \%$, and $1.5 \%\left(39.25,78.50\right.$, and $\left.117.75 \mathrm{~kg} / \mathrm{m}^{3}\right)$ and aspect ratio of 64 are used. These specimens are then tested for static compression and for dynamic impact by split Hopkinson pressure bar (SHPB) at strain rate of 30-60 s $\mathrm{s}^{-1}$. The results reveal that the failure mode of concrete considerably changes from brittle to ductile with the addition of steel fibers. The plain concrete may fail under low-strain-rate single impact whereas the fibrous concrete can resist impact at high strain rate loading. It is shown that strain rate has great influence on concrete strength. Besides, toughness energy is proportional to the fiber content in both static and dynamic compressions.

\section{Introduction}

High-performance concrete (HPC) is a relatively new construction material. Technology for producing HPC has sufficiently advanced that concretes with compressive strengths, $f_{c}^{\prime}$, of more than $50 \mathrm{MPa}$ with slump at $200 \mathrm{~mm}$ are commercially available, and strengths much higher than that but with high workability can be produced easily. Fly ash (FA), an industrial waste has been widely used all over the world as partial cement replacement in HPC due to its economical and environmental benefits hence, it has drawn great attention and research up to the recent years. The percentage of fly ash replacement used ranges from about $20 \%$ from total cementitious materials (low volume fly ash) to more than $50 \%$ (high volume fly ash). Incorporating low calcium fly ash (ASTM C618 class F) to concrete can result in better workability and durability properties [1]. In low volume fly ash concrete, the fly ash acts as pozzolanic material whereas, in high volume fly ash concrete, only a part of the fly ash reacts in the pozzolanic reaction. The other part does not react and remained as microfiller in the concrete although the specimens are kept cured for a long time [2-4]; thus they do not contribute to strength, at par with HPC with ordinary Portland cement (OPCHPC) [1,5]. Ibrahim et al. [6], however, reported that the strength of mortar with high volume fly ash, if used together with nanosilica, increases compared to plain concrete or mortar. Chindaprasirt et al. [7] reported that the replacement of Portland cement by original fly ash increased the porosity but decreased the average pore size of the paste. Siddique [8] concluded in his study that class F fly ash can be suitably used up to $50 \%$ level of cement replacement in concrete for use in precast elements and reinforced cement concrete construction.

Concrete should be designed to resist and to absorb the energy of manmade and natural forces such as explosion and earthquake [9]. High-performance concrete (HPC) is a type of material with high compressive strength and good in performances but brittle in its nature. Studies have proved that the addition of steel fibers into concrete significantly improved many of the engineering properties of mortar and 
concrete, notably compressive and flexural strength, impact strength, and toughness. Toughness is a measure of the ability of the material to absorb energy during deformation estimated using the area under the stress-strain curve [10]. Karahan and Atiş [1], while studying the properties of polypropylene fiber reinforced fly ash concrete, reported that adding a volume fraction of $0 \%, 0.05 \%$, and $0.10 \%$ polypropylene fiber seemed to slightly increase or maintain the strength, but when $0.20 \%$ of polypropylene fiber was added, the strength reduced. For steel fiber reinforced concrete, there was an increase up to $10 \%$ and reduction up to $6 \%$ compressive strength of cube concrete specimens compared to plain concrete [5].

Generally, the aspect ratio of steel fibers used in concrete mix varied from 50 to 100 . The suitable volume fraction values for concrete mixes are from $0.5 \%$ to $2 \%$ by volume of concrete. The performance and character of steel fiber reinforced high-performance concrete (SFRHPC) varies with different fiber material type, fiber geometry, fiber distribution, fiber orientation, and fiber concentration [11]. Among all major parameters of SFRHPC, the dynamic compressive strength possesses the most important criteria of concrete to resist dynamic loadings of high strain rate. On the other hand, the addition of steel fiber reduces the workability of the concrete $[1,5]$. This can be balanced by the use of fly ash in the mixture of SFRHPC to increase the workability of the concrete [12].

Shkolnik [13] has proposed a CEB model to predict the complete stress-strain curve of HPC grade $70 \mathrm{MPa}$. The CEB model was under dynamic loadings of strain rate ranging from $0.00003 \mathrm{~s}^{-1}$ to $300 \mathrm{~s}^{-1}$. The results showed that the dynamic compressive strength is directly proportional to the strain rate of loadings. Wang et al. [14] experimentally studied the mechanical behaviors of steel fiber reinforced concrete (SFRC) through both static and dynamic compression using SHPB for dynamic compression tests. They reported that the failure mode of SFRC considerably changes from fragile to ductile. The impact properties of SFRC, including dynamic strength and toughness energy, exhibit strong strain-rate dependency.

An area that has not been extensively examined previously is the effect of steel fiber additions on the mechanical and durability properties of fly ash HPC against high strain-rate loadings. Researchers have studied fly ash HPC and SFRC separately; however, considering SFRHPC with fly ash is an area that needs more study. The purpose of this research is to study the effects of steel fibers on the compressive strength, flexural strength, and dynamic compressive strength of SFRHPC with fly ash.

\section{Experimental Programme}

\subsection{Materials}

2.1.1. Cement. The cement used was Portland cement ASTM C type 1 with specific gravity of 3.15. Its Blaine specific surface area is $3250 \mathrm{~cm}^{2} / \mathrm{g}$, and its chemical composition is given in Table 1.
2.1.2. Fly Ash. The fly ash used was obtained from Kapar power station located in Selangor, Malaysia. According to ASTM C 618 standard, it is classified as class F fly ash. The specific gravity and Blaine specific surface area are 2.26 and $2900 \mathrm{~cm}^{2} / \mathrm{g}$, respectively. The chemical oxide composition of cement and fly ash is given in Table 1 . The fly ash was not processed and used as received.

2.1.3. Aggregate. The dry and clean natural river aggregate was used in concrete mixture. The gravel is $10 \mathrm{~mm}$ maximum nominal size with $0.44 \%$ water absorption value, and its relative density at saturated surface dry (SSD) condition is 2.63. The water absorption value of the sand used is $2.12 \%$, and its relative density at SSD condition is 2.57 . The grading of the mixed aggregate is presented in Table 2.

2.1.4. Fibers. The steel fiber is $\mathrm{RC} 65 / 35 \mathrm{BN}$ low carbon type, and its both ends are hooked. The steel fiber length is $35 \mathrm{~mm}$ with diameter of $0.55 \mathrm{~mm}$, aspect ratio of 64 , and density of $78.5 \mathrm{~g} / \mathrm{cm}^{3}$.

2.1.5. Plasticizer. A commercial super plasticizer type $\mathrm{F}$ with the compound of condensed naphthalene sulphate formaldehyde was used to maintain the workability of fresh concrete. The dosage of super plasticizer was kept constant in mass basis, that is, $1 \%$ of the binder content. The aim of keeping the amount of plasticizer constant is to neglect, if any, the influence of plasticizer on the properties of hardened concrete.

2.2. Mixture Composition and Preparation. The concrete composition of each cubic meter of concrete (used as basis) is given in Table 3. The mix design is proportional in accordance with the British Department of Environment method (DoE Method of Concrete Mix Design). The targeted compressive strength of concrete is $50 \mathrm{MPa}$, and hence the water cement ratio is set constant at 0.39 . The binder content of $641 \mathrm{~kg} / \mathrm{m}^{3}$ was determined by setting the water content at $250 \mathrm{~kg} / \mathrm{m}^{3}$ for the desired slump between 60 and $180 \mathrm{~mm}$. As the content of fly ash is replacing the same amount of cement, the water requirement can be reduced. According to DoE Concrete Mix Design method, for every $10 \%$ cement replacement with fly ash, the water content can be reduced accordingly based on the slump required. The water content was reduced by $17.5 \mathrm{~kg} / \mathrm{m}^{3}$ due to the $25 \%$ substitution of cement by fly ash. Super plasticizer added was $1 \%$ of the total weight of binder. Fresh SFRHPC containing $0 \%, 0.5 \%, 1.0 \%$ and $1.5 \%$ steel fiber in volume basis was prepared.

The procedures for mixing the SFRHPC are as follows. First, the gravel and sand were placed in a concrete mixer and dry mixed for 2 minutes. Second, the cement and fiber were spread and mixed with little amount of water (10\%) for approximately 2 minutes. Third, the mixing water $(80 \%)$ was added and mixed for another 2 minutes. Fourth, the remaining mixing water $(10 \%)$ and plasticizer were added and mixed for 3 minutes. Finally, the freshly mixed SFRHPC was cast into the moulds, and the moulds were vibrated to 
TABLE 1: Chemical composition of cement and fly ash (\%).

\begin{tabular}{lccccccccc}
\hline Oxide & $\mathrm{SiO}_{2}$ & $\mathrm{Al}_{2} \mathrm{O}_{3}$ & $\mathrm{Fe}_{2} \mathrm{O}_{3}$ & $\mathrm{CaO}$ & $\mathrm{MgO}$ & $\mathrm{SO}_{3}$ & $\mathrm{~K}_{2} \mathrm{O}$ & $\mathrm{Na}_{2} \mathrm{O}$ & $\mathrm{LOI}$ \\
\hline Cement & 19.71 & 5.20 & 3.73 & 62.99 & 2.54 & 2.72 & 0.90 & 0.25 & 0.99 \\
Fly ash & 52.50 & 22.82 & 5.34 & 7.16 & 2.56 & 0.20 & 0.99 & 0.48 & 3.35 \\
\hline
\end{tabular}

TABLE 2: Mixed aggregate gradations.

\begin{tabular}{lccccccr}
\hline & \multicolumn{7}{c}{ Particle size (mm) } \\
& $0-0.25$ & $0.25-0.5$ & $0.5-1.0$ & $1-2$ & $2-4$ & $4-8$ & $8-16$ \\
\hline Content (\%) & 11.4 & 23.7 & 14.0 & 7.9 & 14.33 & 21.5 & 7.17 \\
\hline
\end{tabular}

TABLE 3: Concrete composition for a cubic meter (mix design of concrete specimens).

\begin{tabular}{lccccccc}
\hline Mixture & $\mathrm{PC}\left(\mathrm{kg} / \mathrm{m}^{3}\right)$ & Fly ash $\left(\mathrm{kg} / \mathrm{m}^{3}\right)$ & $\mathrm{ST} \mathrm{fiber}\left(\mathrm{kg} / \mathrm{m}^{3}\right)$ & $W\left(\mathrm{~kg} / \mathrm{m}^{3}\right)$ & $\mathrm{SP}\left(\mathrm{kg} / \mathrm{m}^{3}\right)$ & Sand $\left(\mathrm{kg} / \mathrm{m}^{3}\right)$ & Gravel $\left(\mathrm{kg} / \mathrm{m}^{3}\right)$ \\
\hline C50F00 & 481 & 160 & 0 & 233 & 6.41 & 785 & 592 \\
C50F05 & 481 & 160 & 39.25 & 233 & 6.41 & 778 & 587 \\
C50F10 & 481 & 160 & 78.50 & 233 & 6.41 & 771 & 581 \\
C50F15 & 481 & 160 & 117.75 & 233 & 6.41 & 763 & 576 \\
\hline
\end{tabular}

remove any trapped air. Each of the specimens was allowed to stand for 24 hours in the laboratory before demolding. Specimens were cured in water at approximately $21-25^{\circ} \mathrm{C}$ for 28 days before testing.

2.3. Testing Methods. The compressive and flexural strength of each specimen was determined based on BS 1881-116: 1983 and BS 1881-118: 1983, respectively. The dynamic compressive strength of each specimen was determined based on ASTM C-39 using SHPB technique at the pressure of $2 \mathrm{MPa}$ and $3 \mathrm{MPa}$. Specimens were cubes of $150 \mathrm{~mm}^{3}$ for compressive strength, prisms with dimensions of $100 \times$ $100 \times 500 \mathrm{~mm}$ for flexural strength, and cylinders with $50 \mathrm{~mm}$ diameter and $50 \mathrm{~mm}$ height for dynamic compression strength. Each test was done on 3 cubes, 3 prisms, and 9 cylinders samples for each steel fiber volume fraction of $0 \%$, $0.5 \%, 1.0 \%$, and $1.5 \%$.

The split hopkinson pressure bar (SHPB) system consists of a launch tube, a striker bar, a transmission bar, and the energy-absorbing parts. The energy source system contains air compressor and pressure vessel. The measurement system comprises velocity and dynamic strain indicator. The Young's modulus of the projectile, incident and transmission bar, is $210.0 \mathrm{GPa}$ and the wave velocity of $5190 \mathrm{~m} / \mathrm{s}$. The schematic arrangement of SHPB system is shown in Figure 1 (all measurements are in $\mathrm{mm}$ ), and Figure 2 shows the orthographic view of the system.

Figure 3 shows the closeup of the incident bar and the transmission bar with the debris of the crushed concrete sample without fiber still in place.

The strain gauges are mounted on to the system at the middle of the incident bar and the transmission bar. When the striker bar hits the end of the incident bar, an elastic compression stress pulse is generated. The shape of this pulse in stress-time coordinates is almost rectangular (sinusoidal Lagrangian wave), and the amplitude is proportional to the impact velocity of the striker bar. This pulse propagates through the specimen. When the incident pulse reaches the interface of the incident bar and specimen, a portion of the pulse is reflected back along the incident bar as a tensile pulse and the remaining portion is transmitted into the specimen as a compressive wave through the transmission bar. The incident pulse is made sure not to overlap with the reflected pulse. The strain signal is recorded using a high-speed digital oscilloscope of 10 bit. To reduce the noise vibration, the input wave difference in the oscilloscope is established. The incident bar and the transmission bar maintain their elasticity during the test such that the ratio between the length and diameter of the bar is designed to be sufficiently large $(1400 \mathrm{~mm} / 100 \mathrm{~mm})$. Then, the following assumptions are made.

(1) The wave propagation in the bars is well approximated by one-dimensional wave propagation theory.

(2) The stress and strain in the specimens are uniform in the axial direction.

(3) The radial inertia and friction effects of the specimen are negligible.

These strain measurements are used to determine the time histories of the stress, strain, and strain rate in the specimen during deformation. Specifically, the stress and strain histories are, respectively,

$$
\begin{gathered}
\sigma(t)=E_{b} \frac{A_{b}}{2 A}\left(\varepsilon_{i}+\varepsilon_{r}+\varepsilon_{T}\right), \\
\varepsilon(t)=\frac{-c_{b}}{L}\left(\varepsilon_{i}+\varepsilon_{r}+\varepsilon_{R}\right),
\end{gathered}
$$

where $\varepsilon_{T}$ and $\varepsilon_{R}$ are the amplitudes of the transmitted and reflected strain pulses. $E_{b}, A_{b}$, and $c_{b}$ are the Young's modulus, cross-sectional area, and longitudinal wave speed of the bars, and $A$ and $L$ are the cross-sectional area and 


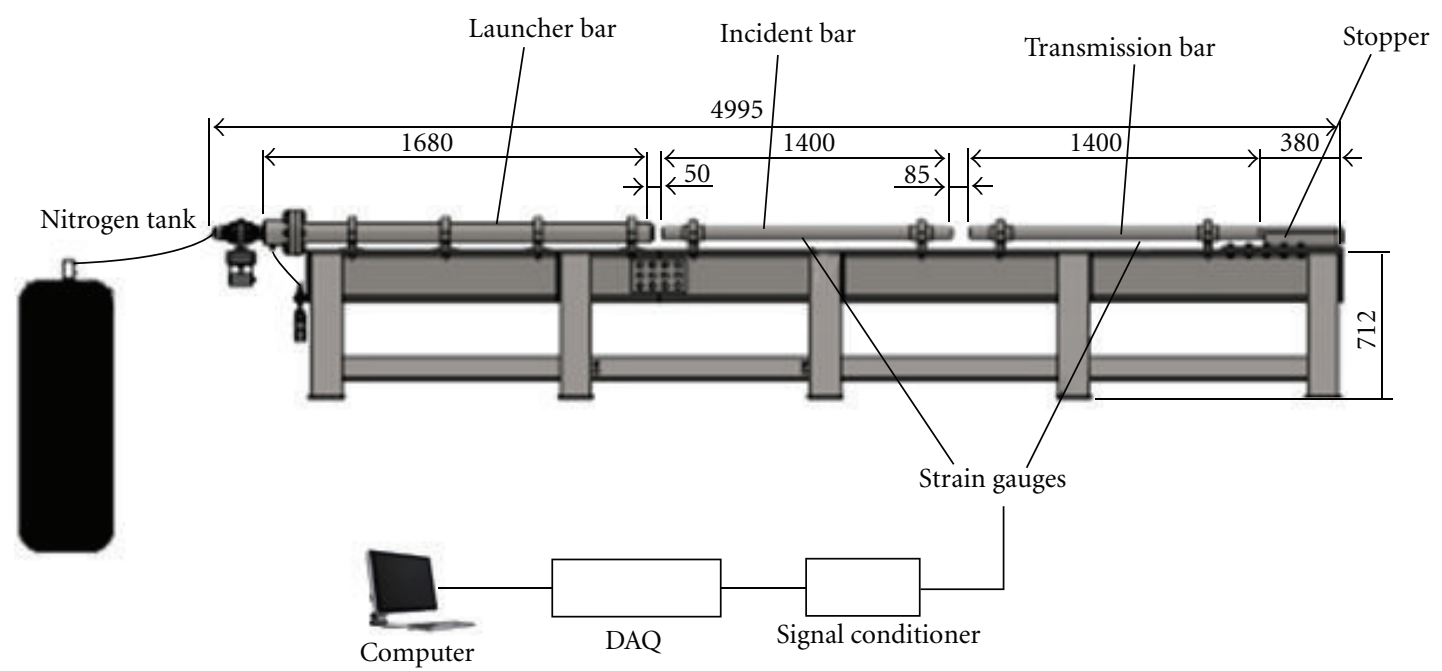

FIGURE 1: Schematic diagram of split Hopkinson pressure bar system (all measurements are in mm).

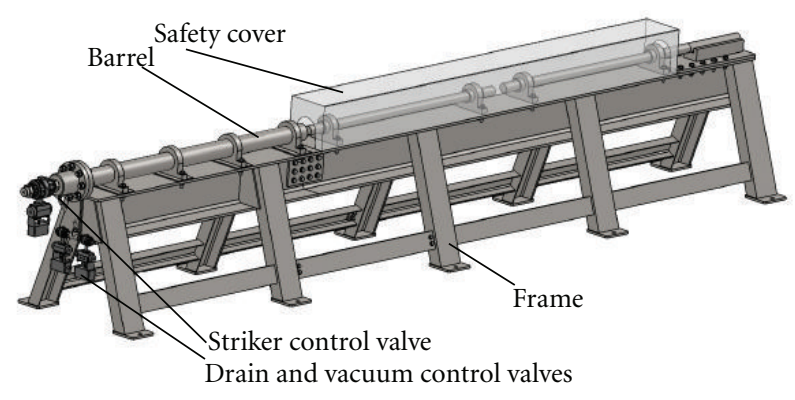

FIGURE 2: The orthographic view of the SHPB system.

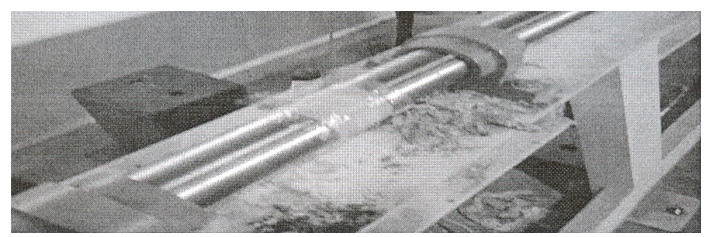

FIgURE 3: Incident bar and transmission bar.

length of the specimen, respectively. The expression for the strain rate in (2) may be integrated with respect to time to give the strain:

$$
\varepsilon(t)=\frac{-c_{b}}{L} \int_{0}^{t}\left(\varepsilon_{i}-\varepsilon_{r}-\varepsilon_{T}\right) d t .
$$

The specimen must be short enough for a uniform state of stress along the length of the specimen to be rapidly achieved during loading. Five-to-ten wave reverberations within the specimen are normally required [15]. On the other hand, when very short specimens are used, friction between the specimen ends and the bars can play a significant role and lead to an apparent increase in strength [16]. The diameter of the specimen also needs to be small relative to the wavelength of the applied load pulse for the one-dimensional wave theory to be valid without the complication of PochhammerChree radial oscillations [17]. The Pochhammer-Chree solutions are used to describe longitudinal axially symmetric wave propagation in solid cylinders. To avoid dispersion wave, Davies and Hunter [17] suggested that the optimum aspect ratio be

$$
\frac{L}{D}=\sqrt{\frac{3}{4}} v,
$$

where $v$ is the Poisson's ratio of the specimen material. In most cases, this condition yields $L / D \approx 0.5$. In the experiments conducted by them, aspect ratios between 0.31 and 1.55 are used to achieve a range of strain rates for the characterization of strain rate sensitivity. Multiple tests show that specimens with aspect ratios in this range yield consistent stress-strain curves for the same strain rate, and no obvious size effect is observed.

The poison ratios of HPC with FA were reported to be lower than the normal concrete indicating the more brittleness of the HPC. Taking HPC poison ratio value of 0.21 , the $L / D$ used in this study is 1.00 thus, the specimen used is $75 \mathrm{~mm} \times \varnothing 75 \mathrm{~mm}$.

\section{Experimental Results and Analysis}

3.1. Static Compressive Strength. The average compressive strength of the three concrete cubes for each mix is measured at the age of 28 days and is shown in Table 4 . The average compressive strength is more than $50 \mathrm{MPa}$ which is the targeted compressive strength at the age of 28 days. The results show that the substitutions of $15 \%$ cement by fly ash did not significantly reduce the compressive strength of HPC. The increase in compressive strength in the fibrous HPC is significant with the fiber volume fraction of $1.5 \%$ and recorded a total of $46 \%$ increase in the specimen C50F15.

3.2. Flexural Strength. The average flexural strength of the three prisms for each concrete mix is measured at the 
TABLE 4: Compressive strength of concrete at 28 days.

\begin{tabular}{lccc}
\hline Specimens & $\begin{array}{c}\text { SF } \\
(\%)\end{array}$ & $\begin{array}{c}\text { Compressive strength } \\
(\mathrm{MPa})\end{array}$ & $\begin{array}{c}\text { Percentage increased } \\
(\%)\end{array}$ \\
\hline C50F00 & 0 & 51.03 & - \\
C50F05 & 0.5 & 65.95 & 29 \\
C50F10 & 1.0 & 70.03 & 37 \\
C50F15 & 1.5 & 74.38 & 46 \\
\hline
\end{tabular}

TABLe 5: Flexural strength of concrete at 28 days.

\begin{tabular}{lccc}
\hline Specimens & $\begin{array}{c}\text { SF } \\
(\%)\end{array}$ & $\begin{array}{c}\text { Flexural strength } \\
(\mathrm{MPa})\end{array}$ & $\begin{array}{c}\text { Percentage increased } \\
(\%)\end{array}$ \\
\hline C50F00 & 0 & 6.00 & - \\
C50F05 & 0.5 & 7.83 & 31 \\
C50F10 & 1.0 & 9.92 & 65 \\
C50F15 & 1.5 & 12.25 & 104 \\
\hline
\end{tabular}

age of 28 days and shown in Table 5. Steel fibers have significant effects on the flexural tensile strength of HPC. The improvement starts from $31 \%$ at $0.5 \%$ and expands to $65 \%$ at $1.0 \%$ and finally to $104 \%$ at $1.5 \%$. The increase in fiber amounts in content results in the further increase in flexural tensile strength in HPC. Randomly distributed steel fiber controls the cracks and snitches them. Therefore, when steel fiber controls the cracks, the load to fail the beam specimen has to be increased to induce more cracks for the failure. Thus, the addition of steel fiber increases the ultimate flexural strength of material. The concrete flexural strength increases to be higher with the higher amount of the steel fiber in the concrete.

3.3. Dynamic Impact Strength. The dynamic impact strength of SFRHPC is focused only on the single impact in this study. In order to achieve the single impact failure on the plain concrete, the pressure of the loading is set at $2 \mathrm{MPa}$ (Figure 4) at first and to $3 \mathrm{MPa}$ (Figure 5) later on to achieve a minimum strain rate of $32.04 \mathrm{~s}^{-1}$. Similarly, the minimum strain rate of fibrous specimens containing volume fraction of $0.5 \%, 1.0 \%$, and $1.5 \%$ is $32.94 \mathrm{~s}^{-1}, 40.02 \mathrm{~s}^{-1}$, and $47.21 \mathrm{~s}^{-1}$, respectively. The impact velocity that can be adjusted by the gas pressure is used to determine the strain rate. Figures 4 and 5 show that the stress-strain curves are linear for all specimens of concrete until the damage threshold is reached and then followed by the softening portion. Also noticing that the plain HPC (C50F00) does not possess a full curve as the fibrous HPC, this shows the brittleness of the plain HPC compared to the fibrous HPC. Both the ascending and descending branches of the stress strain curves are affected by the addition of steel fiber, but most obvious in the descending branch. Another fact is, the dynamic response of the SFRHPC is highly sensitive to strain rate. This can be observed through the peak stress, and the corresponding strain increases significantly with the increase of strain rate. Furthermore, the addition of steel fiber increases the peak stress as well as the compressive strength.

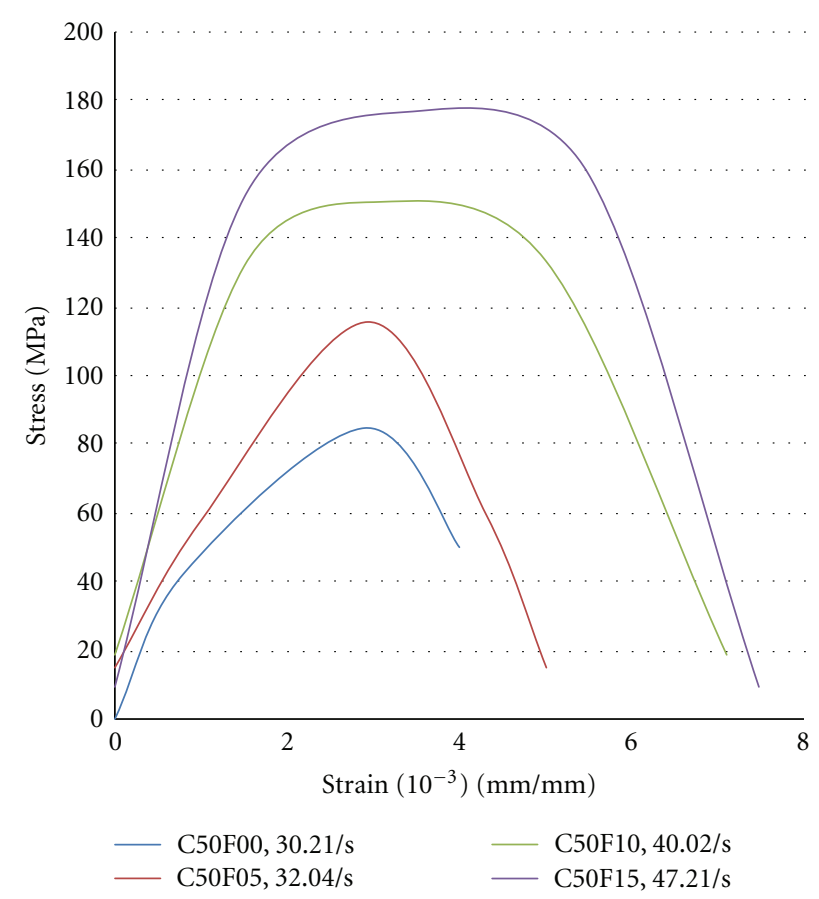

FIGURE 4: Stress-strain curve of SFRHPC under dynamic loadings with strain rate of $30-50 \mathrm{~s}^{-1}$.

The toughness performance of the HPC was observed in the present of steel fiber. Besides, the toughness energy also increases with the increase of strain rate. It is found that the increase in fiber content also results in higher strain rate loading to completely fail the specimen. Finally, the volume fraction of fibers has an essential role on the failure pattern of the concrete. Observation made shows that the plain concrete broke into pieces while the specimen with the volume fraction of $1.0 \%$ still remained the overall outline with small segments peel off. The specimen with fiber volume fraction of $1.5 \%$ kept most of its appearance.

\section{Conclusion}

It is vital to study how the stress-strain relationship of SFRHPFAC reacts under static-dynamic compression. The following conclusion can be drawn from this experimental study.

(1) The static compressive strength tests and flexural strength tests show that the failure mode of SFRHPFAC considerably changes from brittle to ductile. Due to fibers spreading uniformly in the mixture of HPC, the bridging system in the SFRHPFAC made the fibrous specimens essentially intact and bind well to each other.

(2) The addition of steel fiber in concrete mix significantly improves the mechanical properties of HPFAC under static and dynamic loadings. Under the same pressure and approximately same loading strain-rate, the plain HPFAC may fail in a single impact while the SFRHPFAC can resist repeated impacts before failure. 


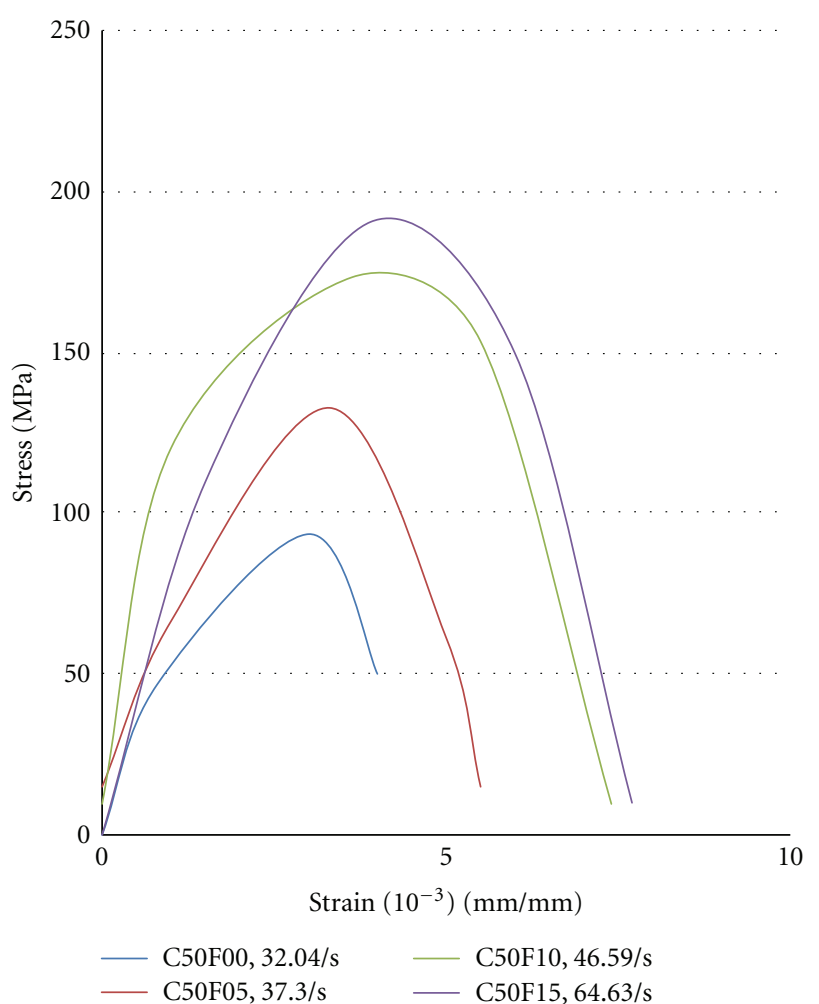

FIGURE 5: Stress-strain curve of SFRHPC under dynamic loadings with strain rate of $30-60 \mathrm{~s}^{-1}$.

(3) The impact properties of SFRHPFAC, including dynamic strength and toughness energy, exhibit strong strain rate dependency. The content of steel fiber in the mixture of HPFAC significantly influenced the performance of HPFAC.

\section{Acknowledgments}

This research is sponsored by Universiti Kebangsaan Malaysian and the Ministry of Higher Learning Malaysia through Projects UKM-GUPBTT-07-25-023 and FRGS/1/ 2011/TK/UKM/02/16.

\section{References}

[1] O. Karahan and C. D. Atiş, "The durability properties of polypropylene fiber reinforced fly ash concrete," Materials and Design, vol. 32, no. 2, pp. 1044-1049, 2011.

[2] L. Lam, Y. L. Wong, and C. S. Poon, "Effect of fly ash and silica fume on compressive and fracture behaviors of concrete," Cement and Concrete Research, vol. 28, no. 2, pp. 271-283, 1998.

[3] V. G. Papadakis, "Effect of fly ash on Portland cement systems: part I. Low-calcium fly ash," Cement and Concrete Research, vol. 29, no. 11, pp. 1727-1736, 1999.

[4] C. S. Poon, L. Lam, and Y. L. Wong, "A study on high strength concrete prepared with large volumes of low calcium fly ash," Cement and Concrete Research, vol. 30, no. 3, pp. 447-455, 2000.
[5] C. D. Atiş and O. Karahan, "Properties of steel fiber reinforced fly ash concrete," Construction and Building Materials, vol. 23, no. 1, pp. 392-399, 2009.

[6] R. K. Ibrahim, R. Hamid, and M. R. Taha, "Fire resistance of high-volume fly ash mortars with nanosilica addition," Construction and Building Materials, vol. 36, pp. 779-786, 2012.

[7] P. Chindaprasirt, C. Jaturapitakkul, and T. Sinsiri, "Effect of fly ash fineness on compressive strength and pore size of blended cement paste," Cement and Concrete Composites, vol. 27, no. 4, pp. 425-428, 2005.

[8] R. Siddique, "Performance characteristics of high-volume Class F fly ash concrete," Cement and Concrete Research, vol. 34, no. 3, pp. 487-493, 2004.

[9] Z. Xu, H. Hao, and H. Li, "Experimental study of dynamic compressive properties of fibre reinforced concrete material with different fibres," Materials \& Design, vol. 33, pp. 42-55, 2012.

[10] M. C. Nataraja, N. Dhang, and A. P. Gupta, "Stress-strain curves for steel-fiber reinforced concrete under compression," Cement and Concrete Composites, vol. 21, no. 5-6, pp. 383-390, 1999.

[11] R. F. Zollo, "Fiber-reinforced concrete: an overview after 30 years of development," Cement and Concrete Composites, vol. 19, no. 2, pp. 107-122, 1997.

[12] I. B. Topçu and M. Canbaz, "Effect of different fibers on the mechanical properties of concrete containing fly ash," Construction and Building Materials, vol. 21, no. 7, pp. 14861491, 2007.

[13] I. E. Shkolnik, "Influence of high strain rates on stressstrain relationship, strength and elastic modulus of concrete," Cement and Concrete Composites, vol. 30, no. 10, pp. 10001012, 2008.

[14] Z. L. Wang, Z. M. Shi, and J. G. Wang, "On the strength and toughness properties of SFRC under static-dynamic compression," Composites Part B, vol. 42, no. 5, pp. 1285-1290, 2011.

[15] U. S. Lindholm, "High strain rate tests," in Measurement of Mechanical Properties, R. F. Bunshah, Ed., vol. 5, part 1, New York, NY, USA, 1971.

[16] L. D. Bertholf and C. H. Karnes, "Two-dimensional analysis of the split hopkinson pressure bar system," Journal of the Mechanics and Physics of Solids, vol. 23, no. 1, pp. 1-19, 1975.

[17] E. D. H. Davies and S. C. Hunter, "The dynamic compression testing of solids by the method of the split Hopkinson pressure bar," Journal of the Mechanics and Physics of Solids, vol. 11, no. 3, pp. 155-179, 1963. 

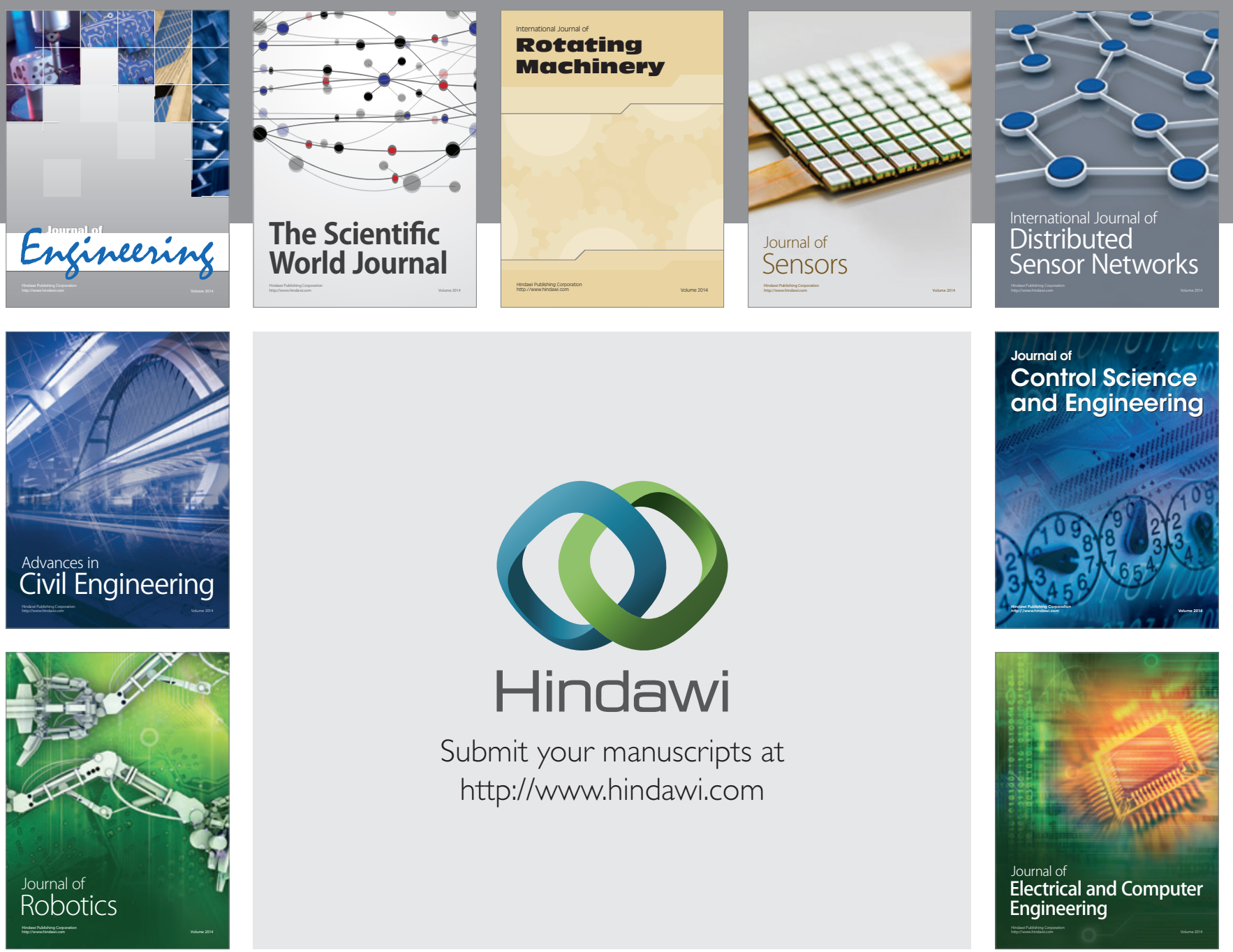

Submit your manuscripts at

http://www.hindawi.com
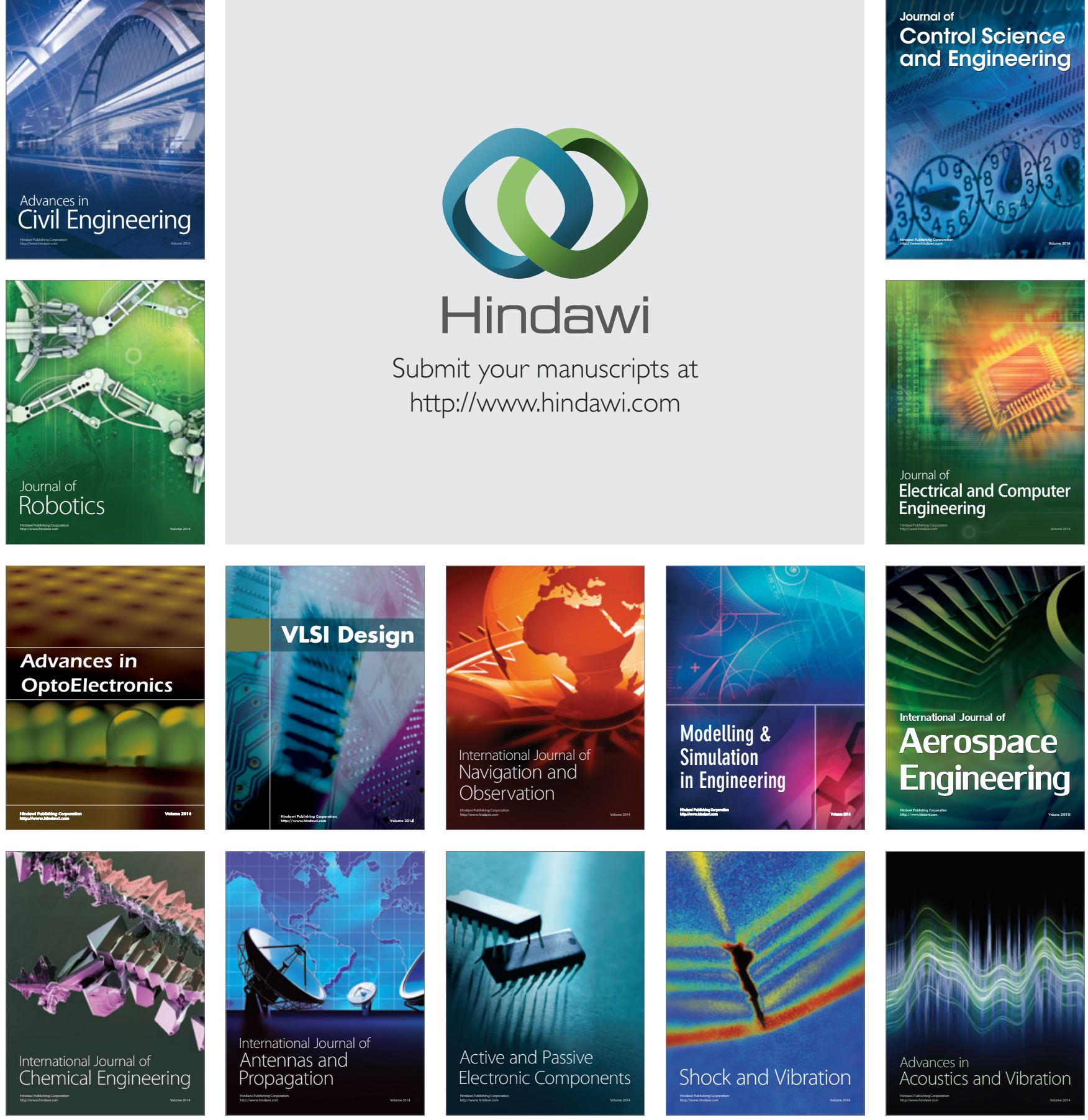